\title{
HDlive for Assessment of Placenta and Umbilical Cord
}

\author{
${ }^{1}$ Toshiyuki Hata, ${ }^{2}$ Hirokazu Tanaka, ${ }^{3}$ Masato Mashima, ${ }^{4}$ Kenji Kanenishi, ${ }^{5}$ Genzo Marumo
}

\begin{abstract}
We present the latest HDlive images of normal and abnormal placentas and umbilical cords. By means of HDlive, more detailed information on placental and umbilical cord abnormalities can be obtained, because this technique is a new surfacerendering mode that uses an adjustable light source to create lighting and shadowing effects, thereby increasing depth perception. HDlive provides extraordinarily realistic imaging of the placenta and umbilical cord, making it almost impossible to differentiate between fetoscopic findings and ultrasound scans. This novel technique may assist in evaluation of the placental and umbilical cord anatomy, and offer potential advantages over conventional two- and three-dimensional ultrasound. HDlive may be an important modality in future placental and umbilical cord research and in the evaluation of their abnormalities.
\end{abstract}

Keywords: Two-dimensional ultrasound, Three-dimensional ultrasound, HDlive, Placenta, Umbilical cord.

How to cite this article: Hata T, Tanaka H, Mashima M, Kanenishi K, Marumo G. HDlive for Assessment of Placenta and Umbilical Cord. Donald School J Ultrasound Obstet Gynecol 2014;8(4):391-399.

Source of support: Nil

Conflict of interest: None declared

\section{INTRODUCTION}

There have been numerous studies on conventional three-dimensional (3D) sonographic diagnosis of normal and abnormal placentas and umbilical cords. ${ }^{1-9}$ Three-dimensional ultrasound has the potential to provide improved visualization of the placental and umbilical cord anatomic morphology compared to twodimensional (2D) sonographic imaging. ${ }^{10}$

HDlive, the latest ultrasound technology, facilitates the creation of clearer placental and umbilical cord images than those obtained using conventional 3D ultrasound owing to better depth perception and the depiction of

\footnotetext{
${ }^{1}$ Professor and Chairman, ${ }^{2,4}$ Associate Professor

${ }^{3}$ Senior Resident, ${ }^{5}$ President

${ }^{1-4}$ Department of Perinatology and Gynecology, Kagawa University Graduate School of Medicine, Miki, Kagawa, Japan

${ }^{5}$ Department of Obstetrics and Gynecology, Marumo Ladies Clinic, Izumi Garden Tower 4F, Tokyo, Japan
}

Corresponding Author: Toshiyuki Hata, Professor and Chairman Department of Perinatology and Gynecology, Kagawa University Graduate School of Medicine, 1750-1 Ikenobe, Miki, Kagawa 761-0793, Japan, Phone: +81-0878912174, e-mail: toshi28@ med.kagawa-u.ac.jp skin-like colors, which gives the placental and umbilical cord images a more realistic appearance. ${ }^{11-15}$ The present paper describes the latest state-of-the-art HDlive imaging of normal and abnormal placentas and umbilical cords, and makes recommendations for future research in this field.

\section{PLACENTA}

Conventional 2D sonography has been widely used to evaluate the placental morphology, anatomy, location, implantation, size, and anomalies during pregnancy. ${ }^{10,16}$ In normal pregnancy, however, 2D sonographic changes of the placenta should not be considered as morphologic hallmarks of placental maturation or aging. ${ }^{17}$ Although, an accurate antenatal diagnosis of placental abnormality can usually be performed in most cases using 2D sonography, more detailed information on placental abnormality is obtained employing 3D ultrasound..$^{10}$ In particular, visualization of the continuity and curvature of placental abnormality is more easily conducted with the 3D surfacerendered mode. ${ }^{2}$ HDlive is a new surface-rendering mode, which uses an adjustable light source that facilitates the ability to create lighting and shadowing effects, thereby increasing depth perception. ${ }^{18}$ This technique provides such extraordinarily realistic imaging of the embryo and fetus that it is almost impossible to differentiate between actual photographs and sonographic images. ${ }^{19}$ The spatial relationship between the intrauterine abnormality and surrounding tissues during pregnancy visualized by HDlive is more readily discernible as compared with conventional 3D sonography. ${ }^{12,14,15}$

\section{Normal Placenta}

Before 10 weeks of gestation, an overall view of the umbilical cord and its attachments to the decidua basalis (primary placenta) and fetal umbilicus could be clearly obtained (Figs 1 to 3). The entire placenta could be identified between 10 and 20 weeks of gestation (Figs 4 to 6). However, depiction of the entire placenta is impossible after 20 weeks of gestation, because the viewing area is limited to that of the 3D probe (Fig. 7). ${ }^{10}$

\section{Chorionic Bump}

A chorionic bump is an irregular, convex bulge passing from the choriodecidual surface into the first-trimester 


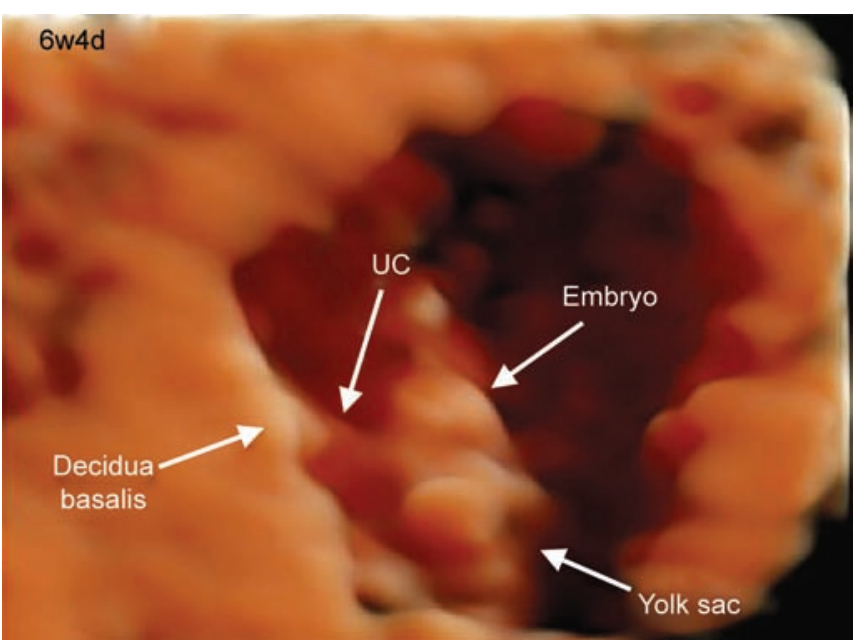

Fig. 1: Normal pregnancy at 6 weeks and 4 days of gestation (UC: Umbilical cord)

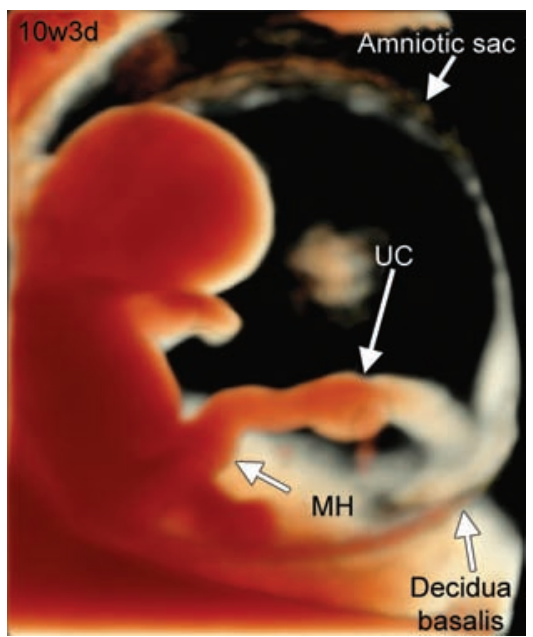

Fig. 3: Normal pregnancy at 10 weeks and 3 days of gestation (MH: Midgut herniation; UC: Umbilical cord)

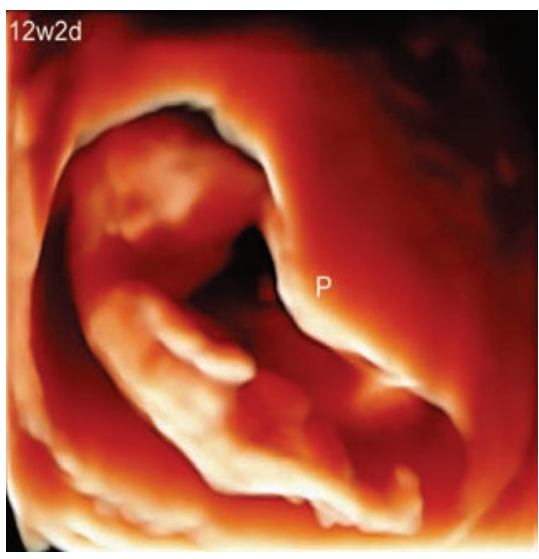

Fig. 5: Normal pregnancy at 12 weeks and 2 days of gestation (P: Placenta)

gestational sac. ${ }^{20}$ Its prevalence is $0.15 \%$, and women with a chorionic bump in the first trimester have approximately double the risk of miscarriage compared with matched controls. ${ }^{21}$ The chorionic bump probably represents a small hematoma that bulges into the gestational sac. ${ }^{20}$

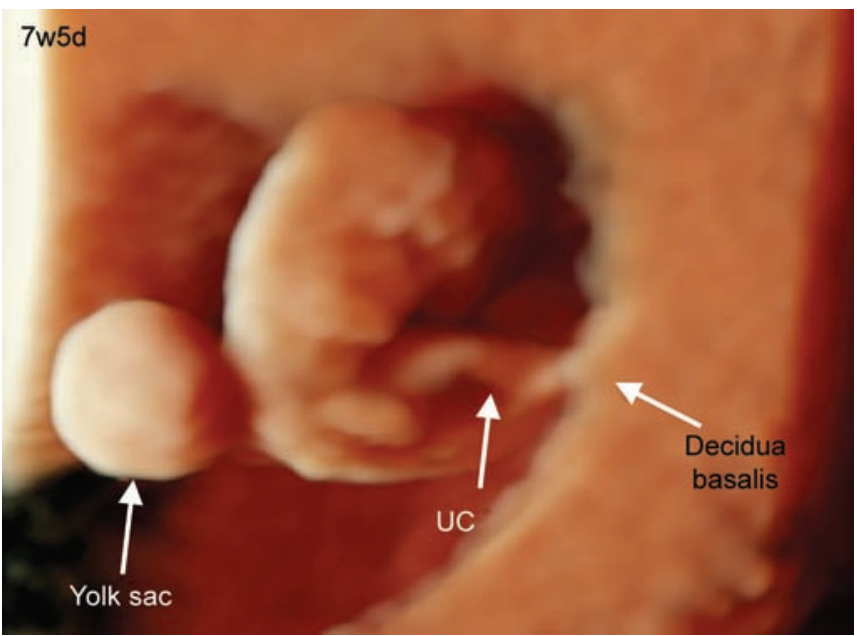

Fig. 2: HDlive image of the embryo and yolk sac at 7 weeks and 5 days of gestation (UC: Umbilical cord) (Courtesy: Reprinted with permission from Hata $\mathrm{T}$ et al) ${ }^{11}$

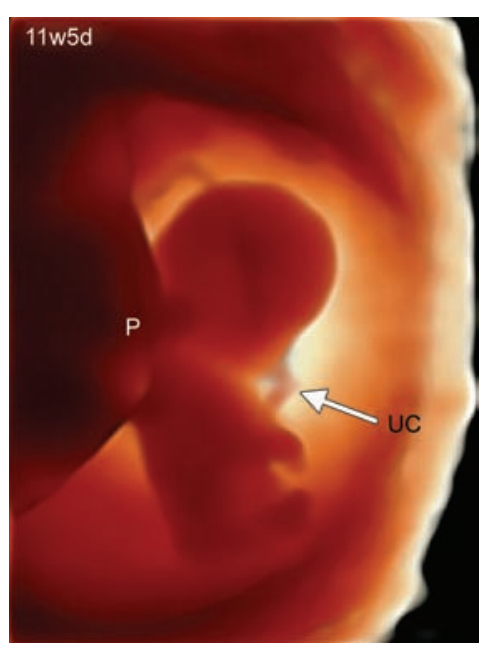

Fig. 4: Normal pregnancy at 11 weeks and 5 days of gestation (P: Placenta; UC: Umbilical cord)
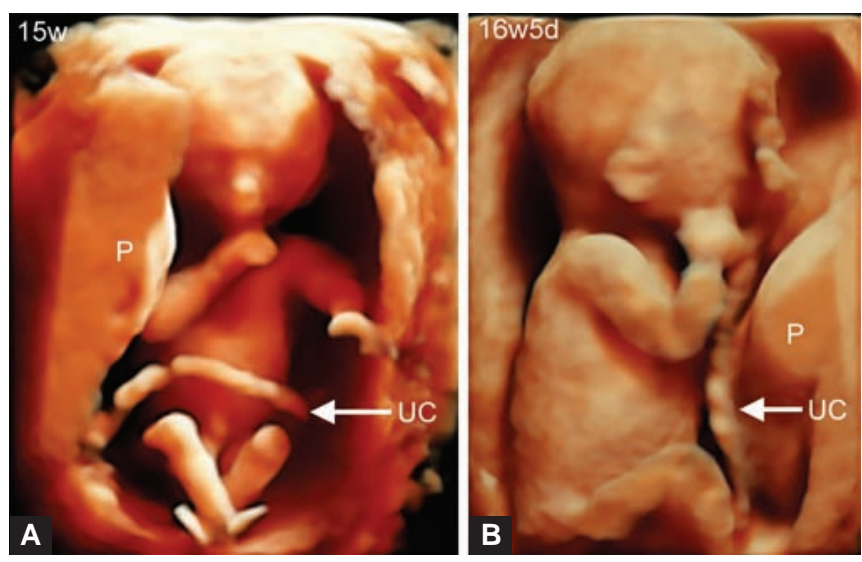

Figs 6A and B: (A) Normal pregnancies at 15 weeks and (B) 16 weeks and 5 days of gestation (P: Placenta; UC: Umbilical cord)

HDlive clearly shows a realistic contour and shape of the chorionic bump, and the spatial relationship between the chorionic bump and embryo is more readily discernible as compared with conventional 2D sonography (Figs 8A to D). 

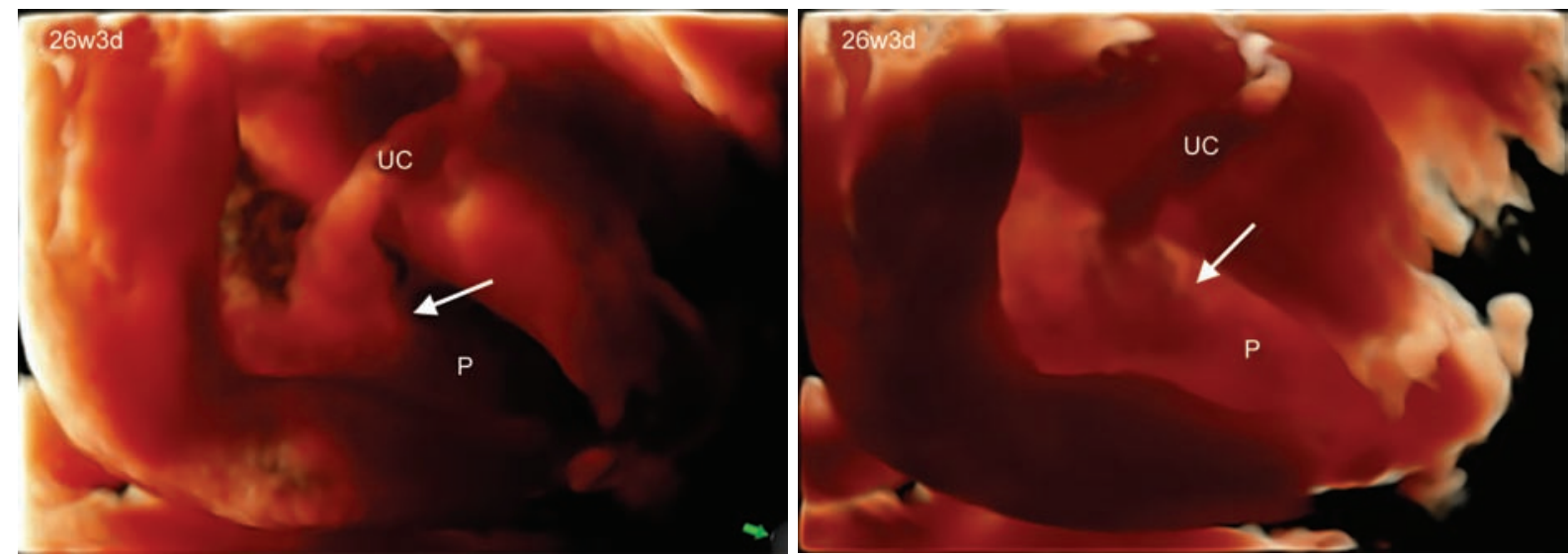

Fig. 7: HDlive images of the placenta with different directions of the light source at 26 weeks and 3 days of gestation. Arrows indicate umbilical cord (UC) insertion into the placenta $(\mathrm{P})$
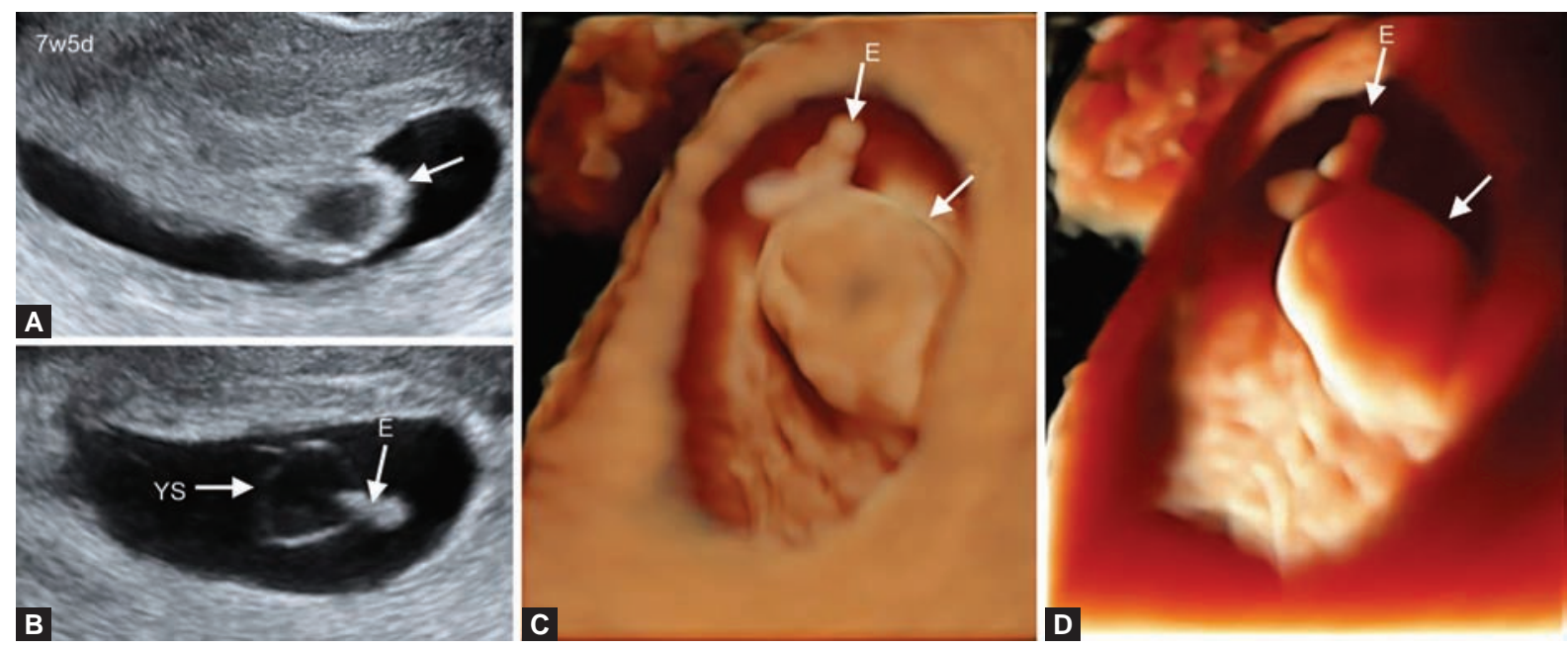

Figs 8A to D: Chorionic bump (arrows) at 7 weeks and 5 days of gestation: (A and B) two-dimensional images and (C and D) HDlive images with different directions of the light source (E: Embryo; YS: Yolk sac)

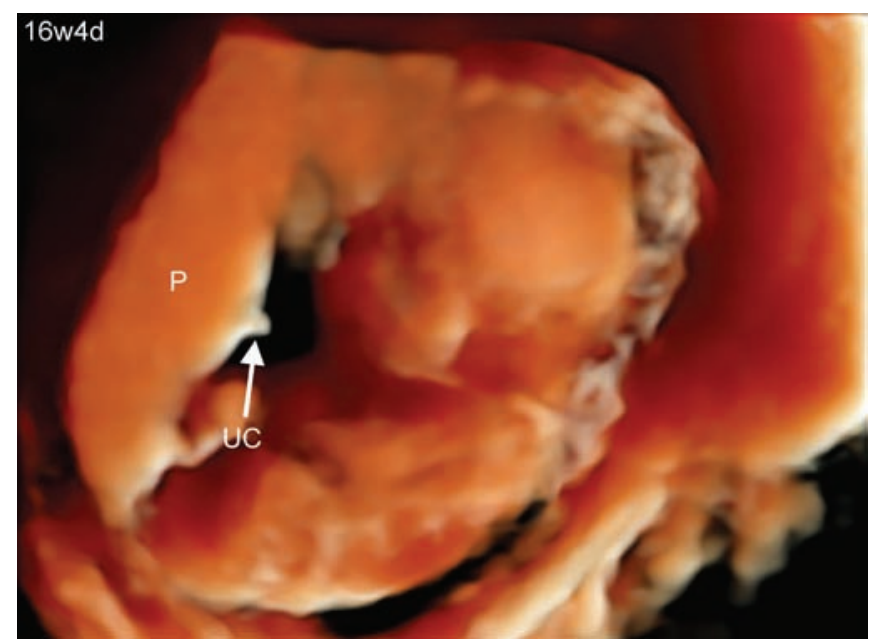

Fig. 9: HDlive image of hydrops fetalis at 16 weeks and 4 days of gestation (P: Placenta; UC: Umbilical cord)

\section{Placenta in a Case of Hydrops Fetalis}

In a case of hydrops fetalis early in the second trimester of pregnancy, a relatively large placenta can be noted using HDlive (Figs 9 and 10).

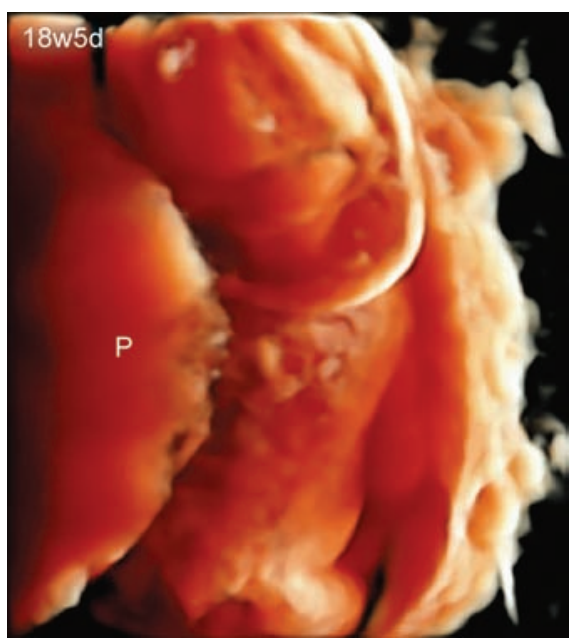

Fig. 10: HDlive image of hydrops fetalis at 18 weeks and 5 days of gestation (P: Placenta)

\section{Large Subchorionic Maternal Lake}

Subchorionic maternal lakes cover from approximately 10 to $50 \%$ of the placental surface, and are 2 to $6 \mathrm{~cm}$ in their longest dimension. ${ }^{22}$ They often contain slow 

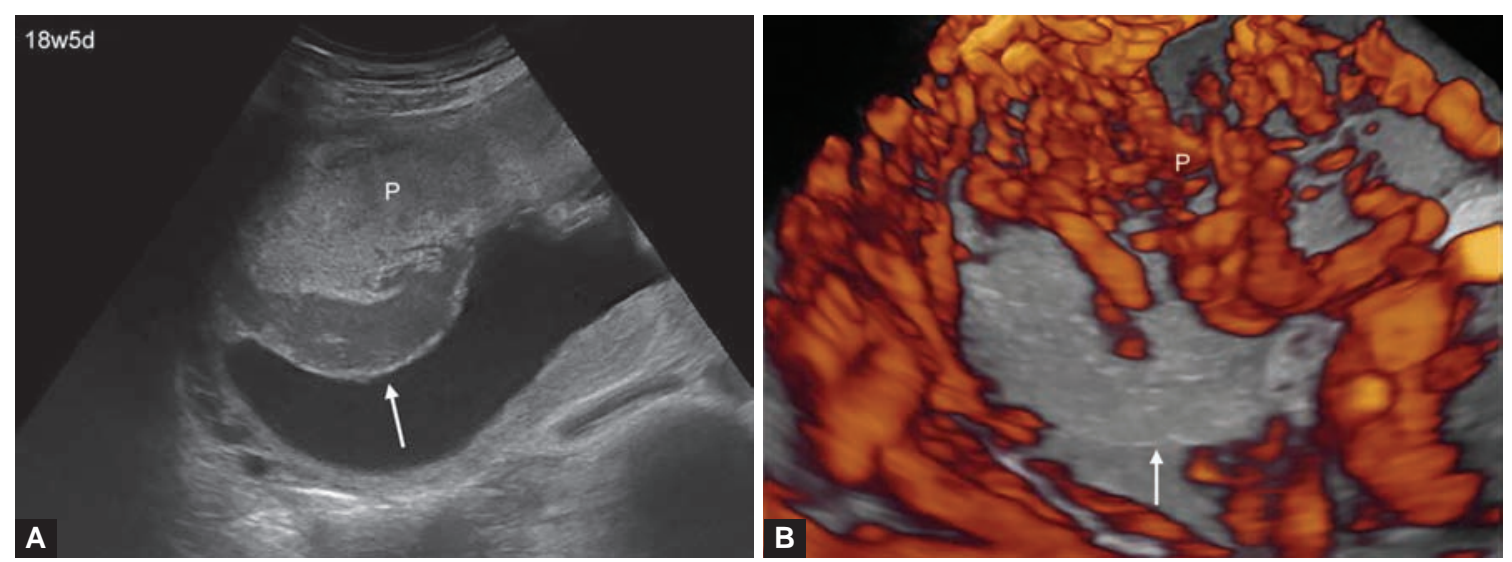

Figs 11A and B: Large subchorionic maternal lake (arrows) at 18 weeks and 5 days of gestation. (A) two-dimensional image and (B) three-dimensional power Doppler sonographic image (P: Placenta)
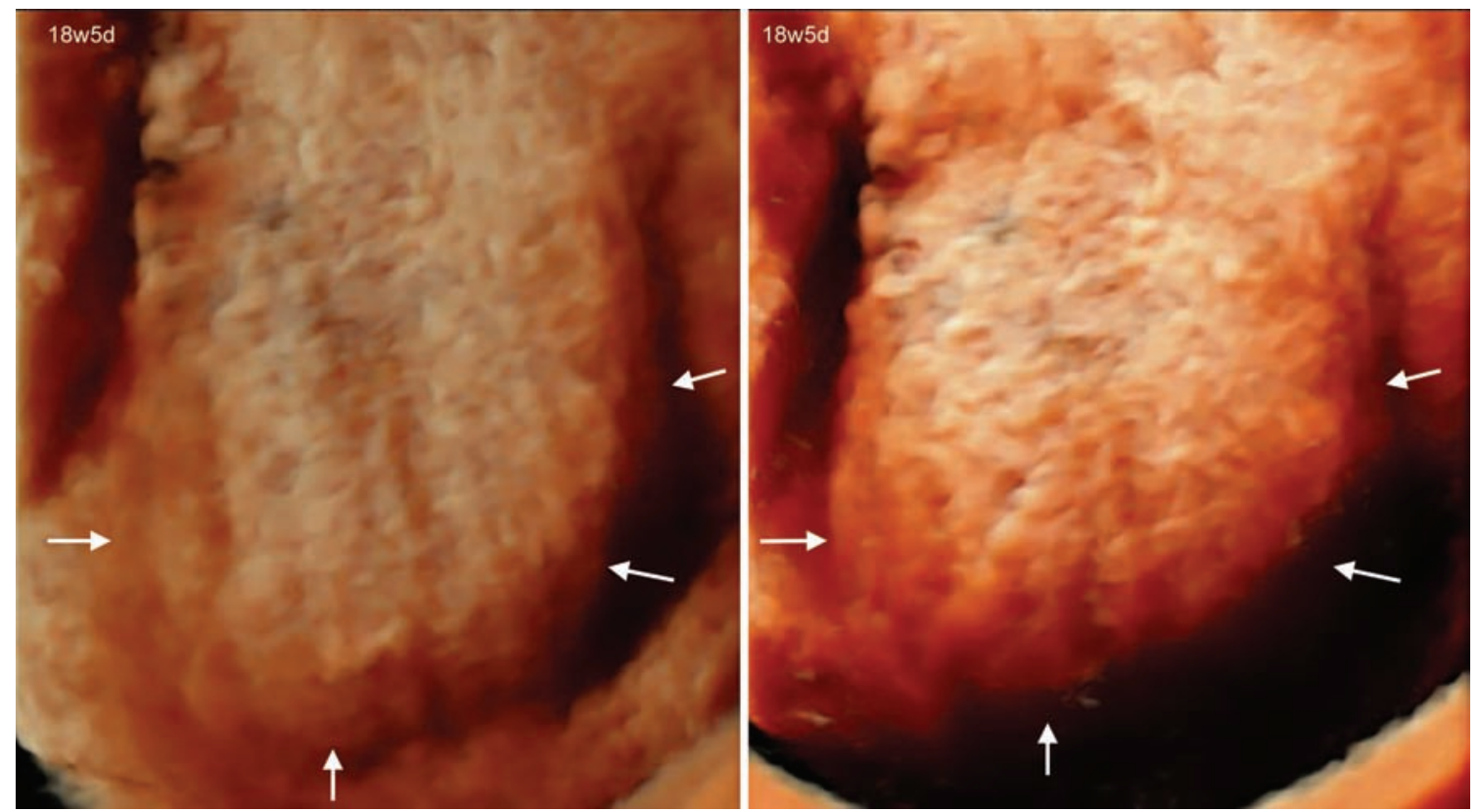

Fig. 12: HDlive images of the large subchorionic maternal lake (arrows) with different directions of the light source at 18 weeks and 5 days of gestation

venous-like flow on real-time sonography. ${ }^{23}$ Subchorionic maternal lakes should be regarded as normal, ${ }^{23}$ although occasionally large echo-free spaces are seen (Figs 11 and 12), and they may be associated with fetal growth restriction and premature delivery. ${ }^{24}$

\section{Placental Shelf}

The 2D sonographic appearance of tissue contiguous with the edge of the placenta that protrudes into the amniotic cavity is called a placental shelf (Figs 13A and B), ${ }^{25}$ and an early second-trimester placental shelf appears to be a common, benign, and transient sonographic finding, which never persists to the third trimester. ${ }^{26}$ There have been only two reports of the antenatal detection of a placental shelf using conventional 3D ultrasound. ${ }^{26,27}$ HDlive provides new, realistic sensations for the diagnosis of a placental shelf, and a near-fetoscopic image of it can be obtained by employing HDlive (Figs 14A and B). ${ }^{12}$

\section{Uterine Synechia}

There have been numerous reports on the antenatal 2D sonographic diagnosis of uterine synechia during pregnancy. ${ }^{28,29}$ However, the spatial relationships among uterine synechia, fetal parts, the umbilical cord, and placenta could not be easily understood with conventional 2D sonography. ${ }^{7,15,30}$ HDlive clearly depicts uterine synechia with umbilical cord prolapse and/or fetal foot prolapse, and provides entirely new visual experiences for the obstetrician and sonographer owing to the anatomically realistic depiction of uterine synechia during pregnancy (Figs 15 to 17). ${ }^{12,15}$ 

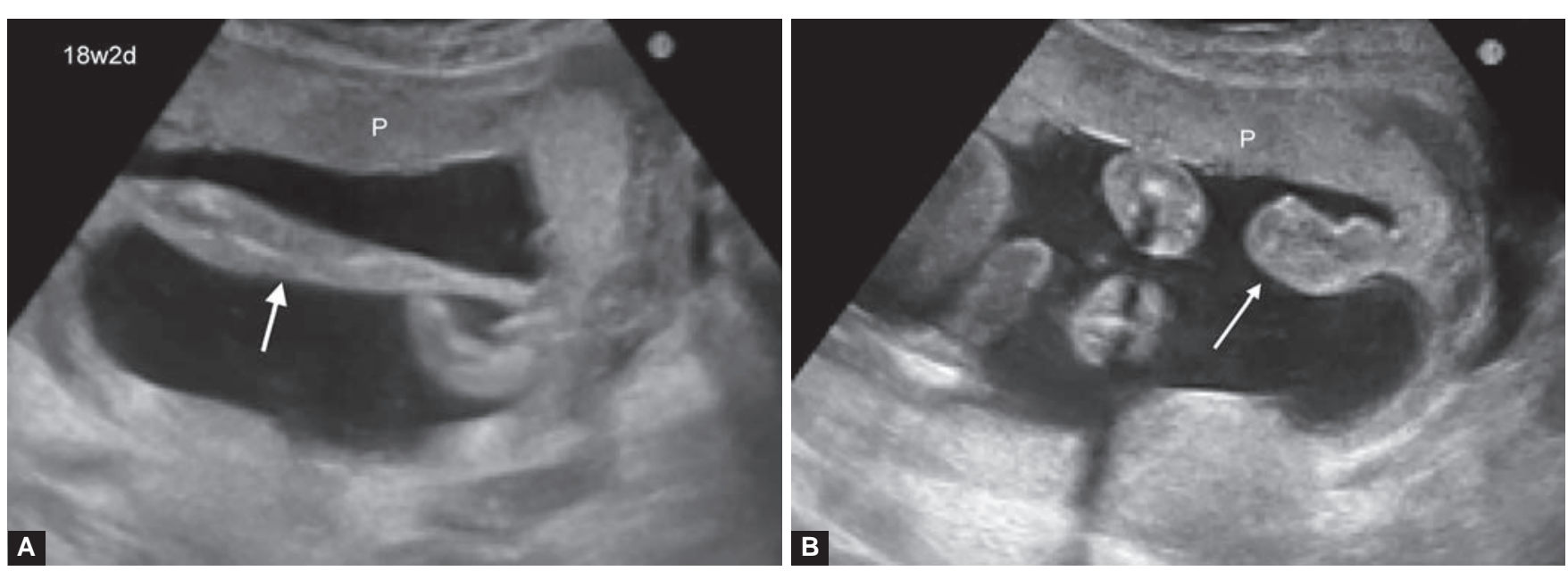

Figs 13A and B: Two-dimensional sonographic transverse (A) and sagittal (B) views of the placental shelf (arrows) at 18 weeks and 2 days of gestation (P: Placenta) (Courtesy: Reprinted with permission from Hata T et al) ${ }^{27}$
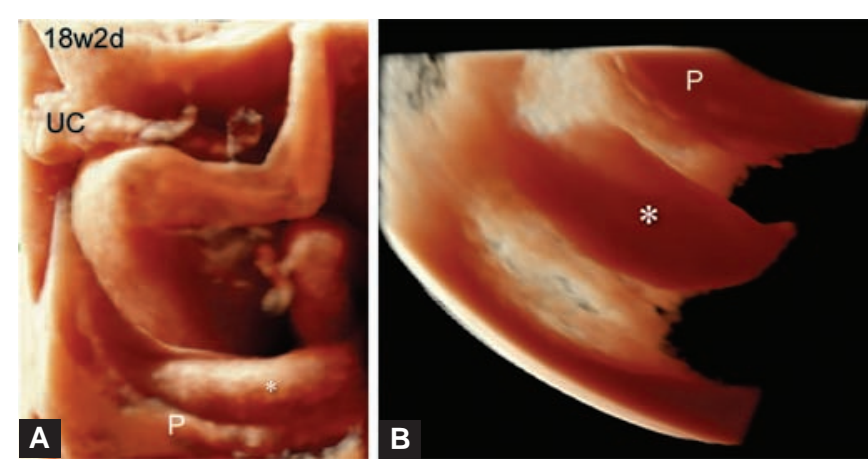

Figs 14A and B: HDlive images of the placental shelf $\left(^{*}\right)$ at 18 weeks and 2 days. A total image of the placental shelf is clearly shown (P: Placenta; UC: Umbilical cord) (A) superior view, (B) frontal view (Courtesy: Reprinted with permission from Hata $\mathrm{T}$ et $\mathrm{al})^{12}$

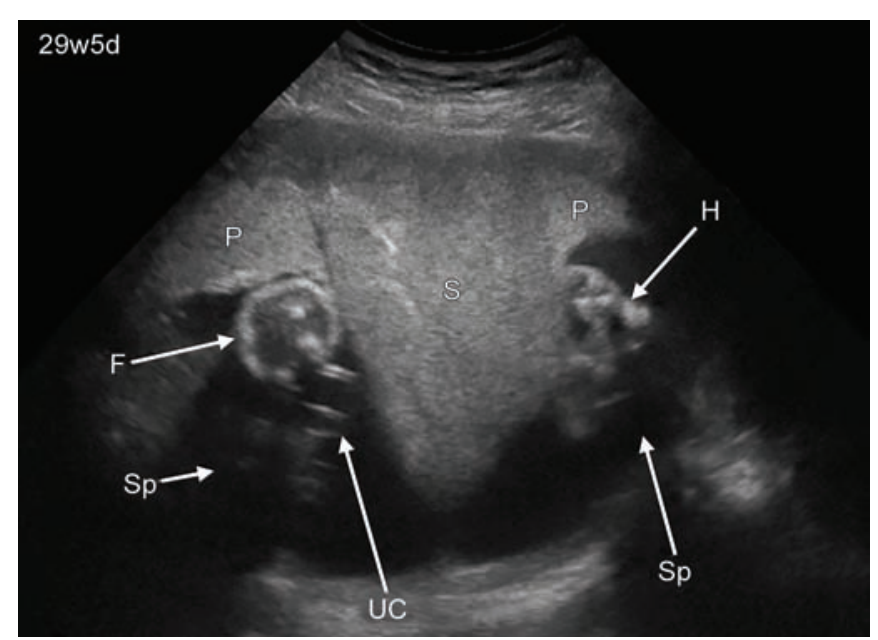

Fig. 16: Vertical, triangular uterine synechia (S) depicted by two-dimensional ultrasound at 29 weeks and 5 days of gestation (F: Foot; H: Hand; P: Placenta; Sp: Space; UC: Umbilical cord) (Courtesy: Reprinted with permission from Hata T et al) ${ }^{15}$

\section{UMBILICAL CORD}

The umbilical cord is a lifeline to the fetus, and its impairment directly affects the fetal life. ${ }^{1}$ Many pathologic
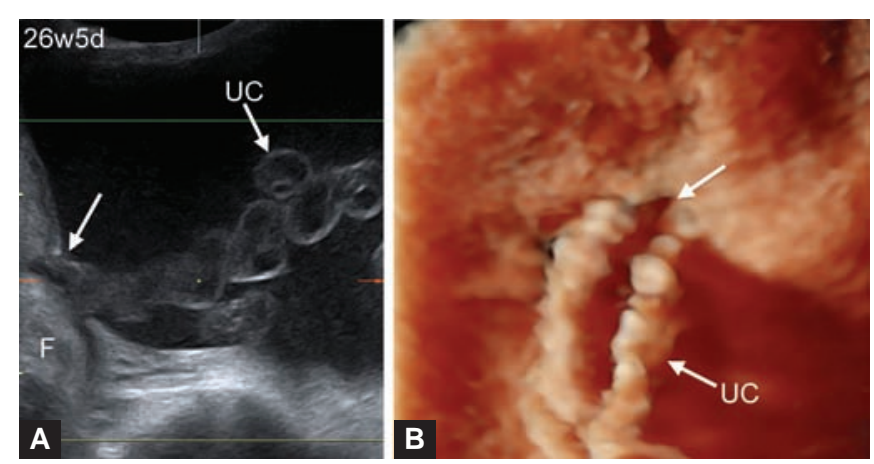

Figs 15A and B: Umbilical cord (UC) prolapse through a transverse uterine synechia (arrows) at 26 weeks and 5 days of gestation. Loops of the umbilical cord are below and the fetus $(F)$ is superior to the uterine synechia: (A) a two-dimensional ultrasound image, (B) HDlive image (Courtesy: Reprinted with permission from Hata T et al $)^{7,12}$

features of the umbilical cord adversely affect fetal wellbeing. ${ }^{31}$ Although, many umbilical cord abnormalities are detectable by conventional 2D sonography, ${ }^{32-35}$ the demonstration of their entire view is impossible, especially in the third trimester of pregnancy. ${ }^{1,4,6,9}$ Three-dimensional ultrasound allows visualization of umbilical cord abnormalities in all three dimensions at the same time, providing an improved overview and a more clearly defined demonstration of adjusted anatomical planes. ${ }^{1,6,36,37}$ HDlive pictures of umbilical cord abnormalities are more readily discernible than those obtained by conventional 3D ultrasound. ${ }^{12,14}$

\section{Normal Umbilical Cord}

HDlive clearly shows developmental changes of the umbilical cord with advancing gestation (Figs 1 to 4, 6, 7, $18,19)$. Cord entanglement during early pregnancy and a hypercoiled umbilical cord can also be clearly visualized employing HDlive (Figs 20 and 21). 

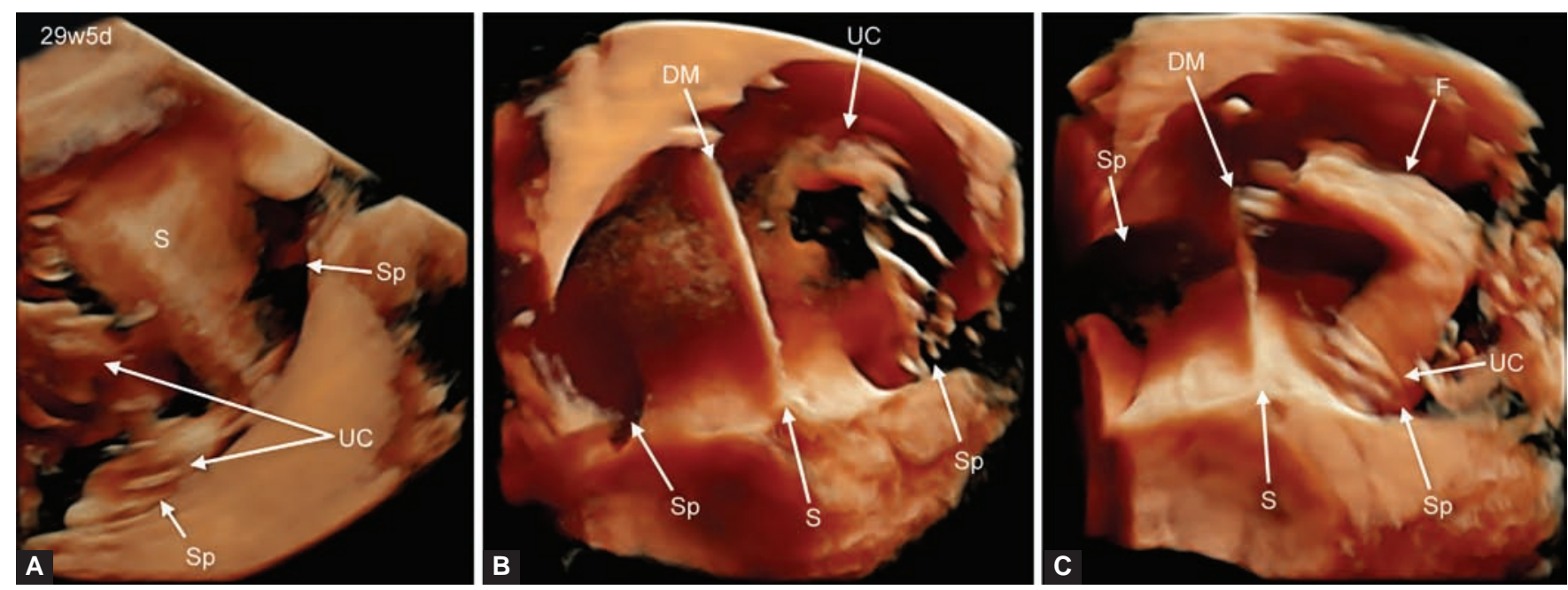

Figs 17A to C: HDlive images of transverse, vertical, and triangular uterine synechia (S) with umbilical cord (UC) and fetal foot (F) prolapses through the right-sided space (Sp). A thin dividing membrane (DM) is noted in the low, liquor-filled amniotic cavity (Courtesy: Reprinted with permission from Hata T et al) ${ }^{15}$
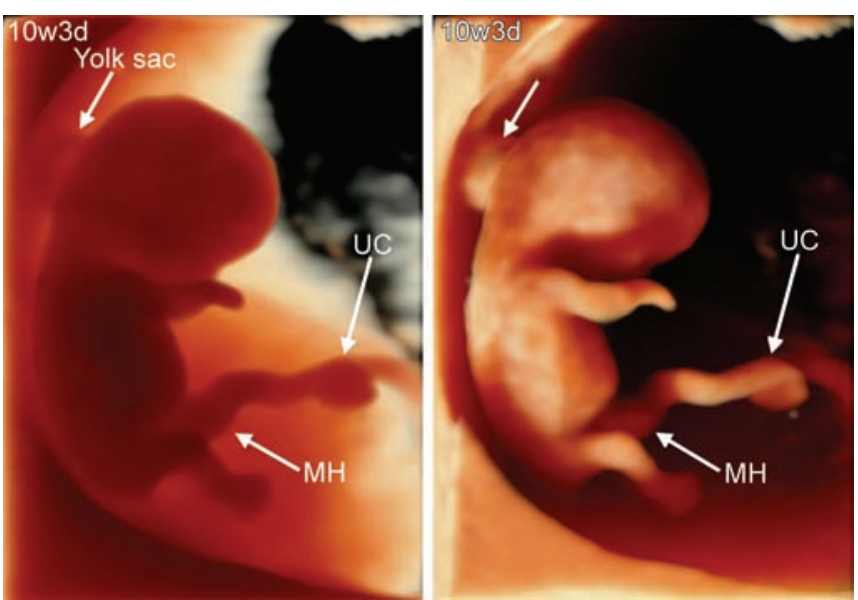

Fig. 18: HDlive images of a normal pregnancy with different directions of the light source at 10 weeks and 3 days of gestation (MH: Midgut herniation; UC: Umbilical cord)

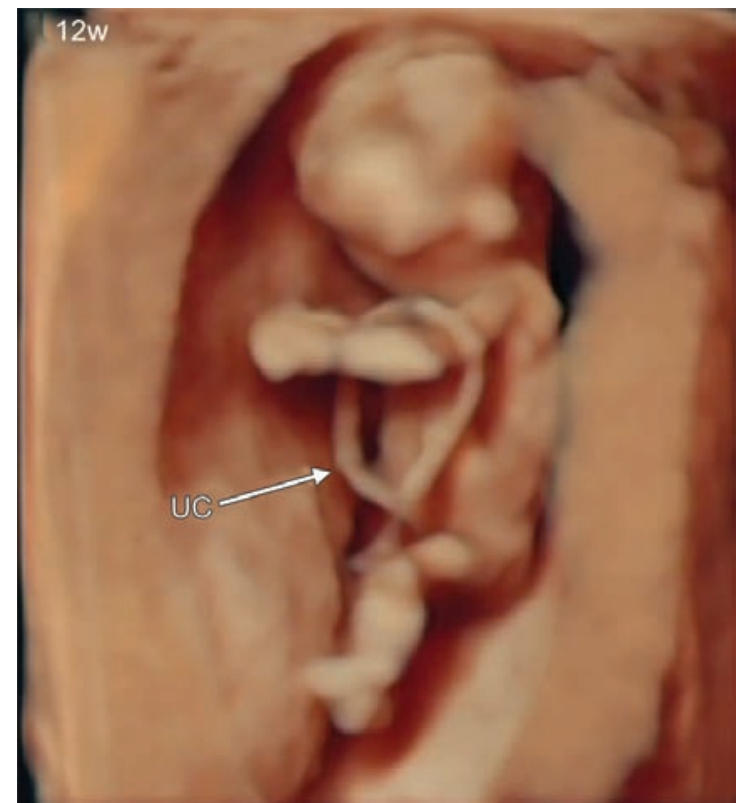

Fig. 20: HDlive image of cord entanglement at 12 weeks of gestation (UC: Umbilical cord)

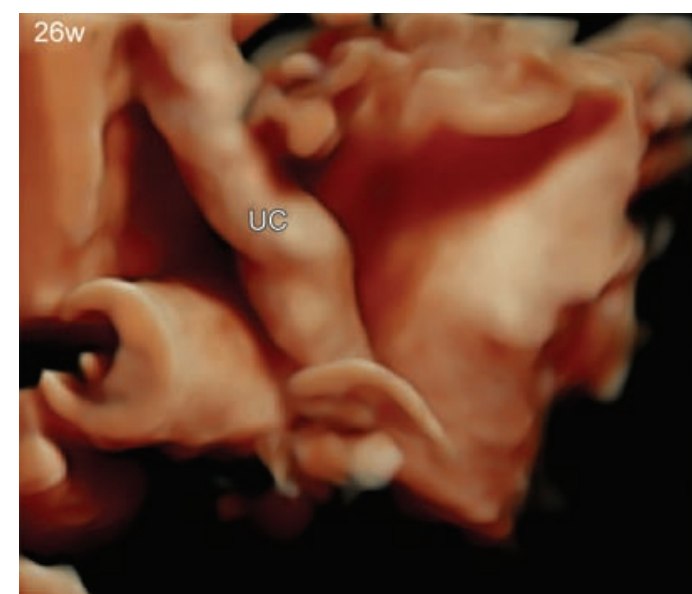

Fig. 19: HDlive image of a normal umbilical cord (UC) at 26 weeks of gestation

\section{Umbilical Cord Edema}

Realistic visualization of umbilical cord edema in a case of hydrops fetalis is possible using HDlive (Fig. 22).

\section{Umbilical Cord Cyst}

HDlive provides a new realistic sensation for the diagnosis of umbilical cord cyst (Figs 23A and B). ${ }^{12,38}$

\section{Intra-amniotic Umbilical Vein Varix}

Intra-amniotic umbilical vein varix is characterized by a high frequency of thrombosis in the varix. ${ }^{14,39-42}$ Conventional 2D sonography shows a large banana-like umbilical cord enlargement including umbilical vein varix with massive thrombosis (Fig. 24). Color Doppler shows bidirectional turbulent blood flow inside the varix (Fig. 25). HDlive clearly demonstrates fragile, massive thrombosis inside the varix (Figs 26A and B). ${ }^{14}$ 

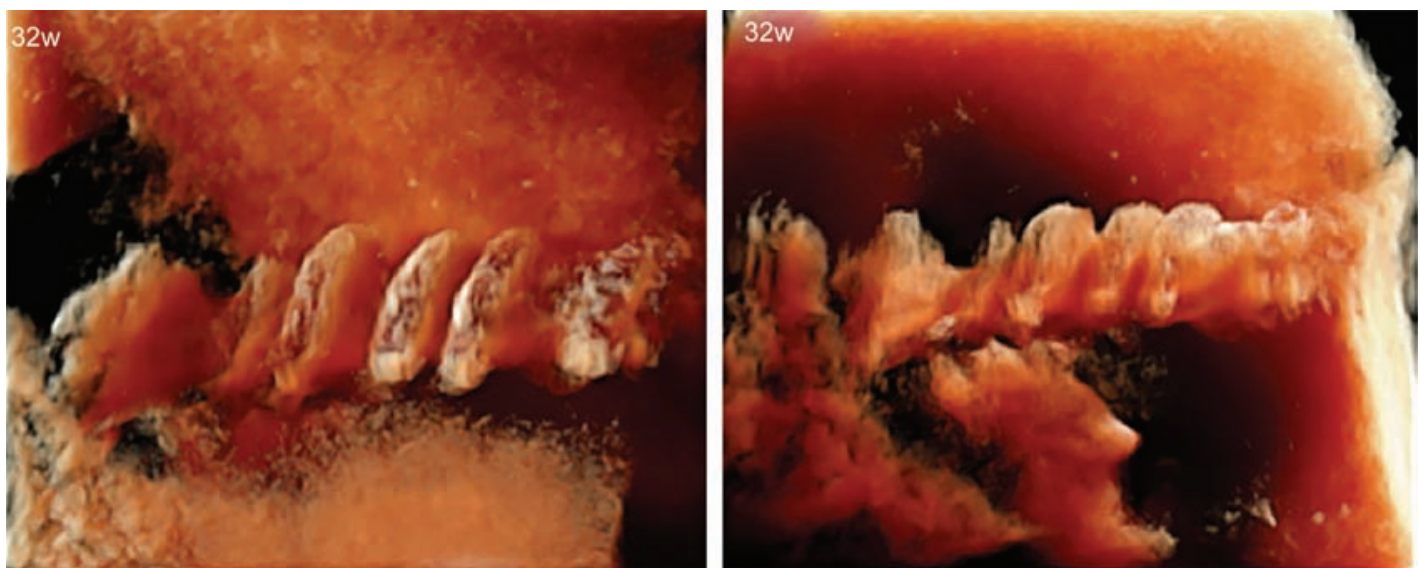

Fig. 21: HDlive images of a hypercoiled umbilical cord with different directions of the light source at 32 weeks of gestation

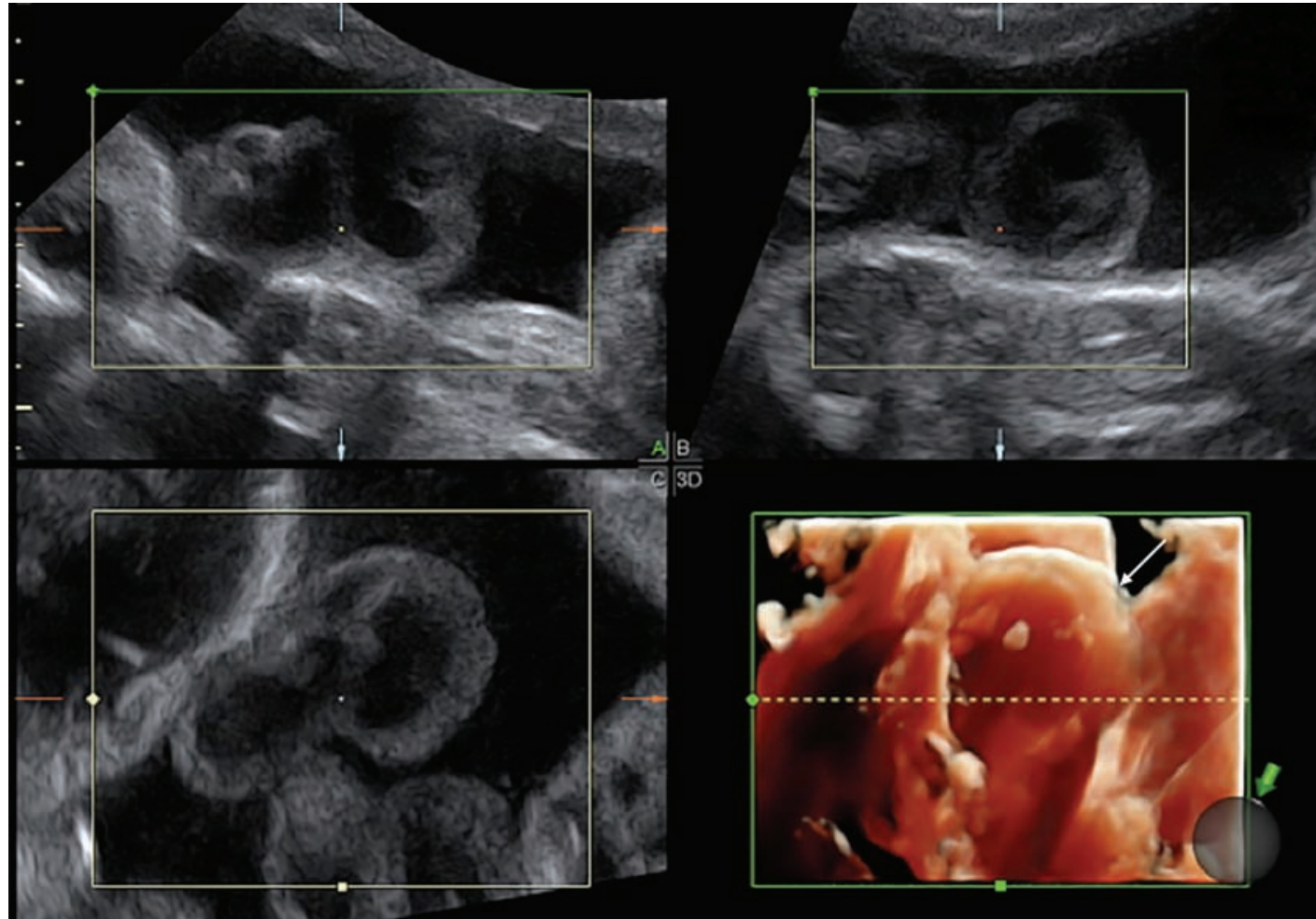

Fig. 22: HDlive image of cord edema in a case (arrow) of hydrops fetalis at 27 weeks and 4 days of gestation

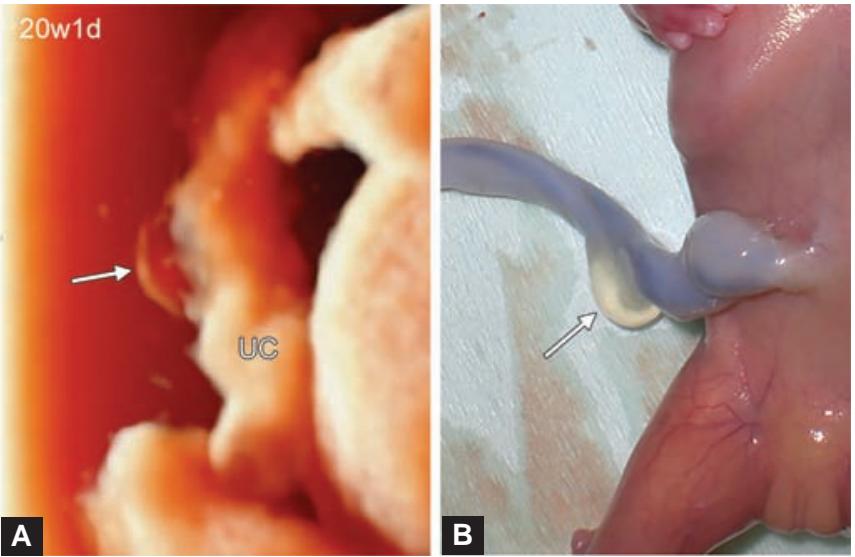

Figs 23A and B: Umbilical cord cyst (arrows) (UC: Umbilical cord). (A) HDlive image at 20 weeks and 1 day of gestation and (B) gross appearance after birth (Courtesy: Reprinted with permission from Hata T et al) $)^{12,38}$

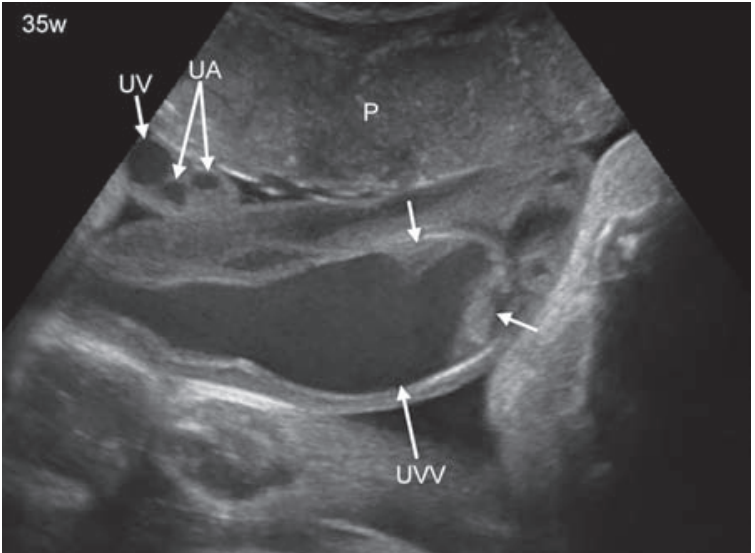

Fig. 24: Two-dimensional sonographic images of intra-amniotic umbilical vein varix (UVV). Massive thrombosis (arrows) is evident inside the varix (P: Placenta; UA: Umbilical artery; UV: Normal umbilical vein) 


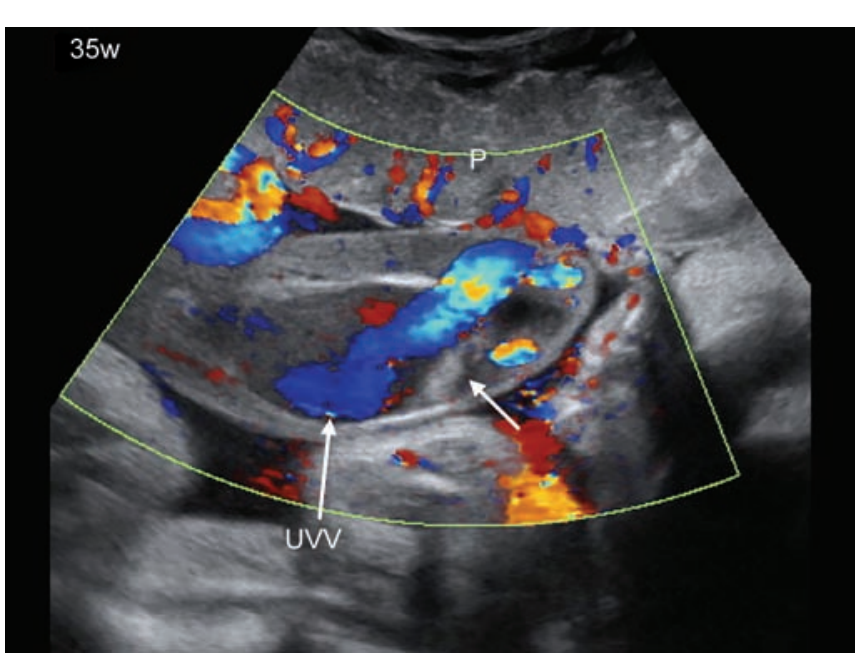

Fig. 25: Color Doppler image of intra-amniotic umbilical vein varix (UVV). Bidirectional turbulent flow inside the varix is clearly identified. Arrow shows thrombosis inside the varix (P: Placenta)

\section{CONCLUSION}

This review article focused on HDlive images of the placenta and umbilical cord. HDlive provides obstetricians with a new, realistic, and arguably much improved, view of the complexities and interrelationships of the placenta and umbilical cord in utero. The present and future application of this novel modality to the prenatal evaluation of normal and abnormal placentas and umbilical cords may be promising. However, this does not suggest that HDlive will replace conventional 2D and 3D sonography. This novel technique may assist in the prenatal diagnosis of abnormal placentas and umbilical cords, and offer potential advantages relative to conventional 2D and 3D sonography, and color/power Doppler ultrasound. Further studies are needed to clarify the present and future application of this modality to antenatal assessment of the placenta and umbilical cord.

\section{ACKNOWLEDGMENTS}

The work reported in this paper was supported by a Grant-in-Aid for Scientific Research on Innovative Areas Constructive Developmental Science (No. 24119004), and a Research Grant (No. 25462561) from the ministry of education, culture, sports, science and technology, Japan.

\section{REFERENCES}

1. Hata T, Aoki S, Hata K, Miyazaki K. Three-dimensional ultrasonographic assessment of the umbilical cord during the 2nd and 3rd trimesters of pregnancy. Gynecol Obstet Invest 1998; 45(3):159-164.

2. Hata T, Kanenishi $K$, Inubashiri E, Tanaka H, Senoh D, Manabe A, Miyake K, Kondoh S. Three-dimensional sonographic features of placental abnormalities. Gynecol Obstet Invest 2004; 57(2):61-65.

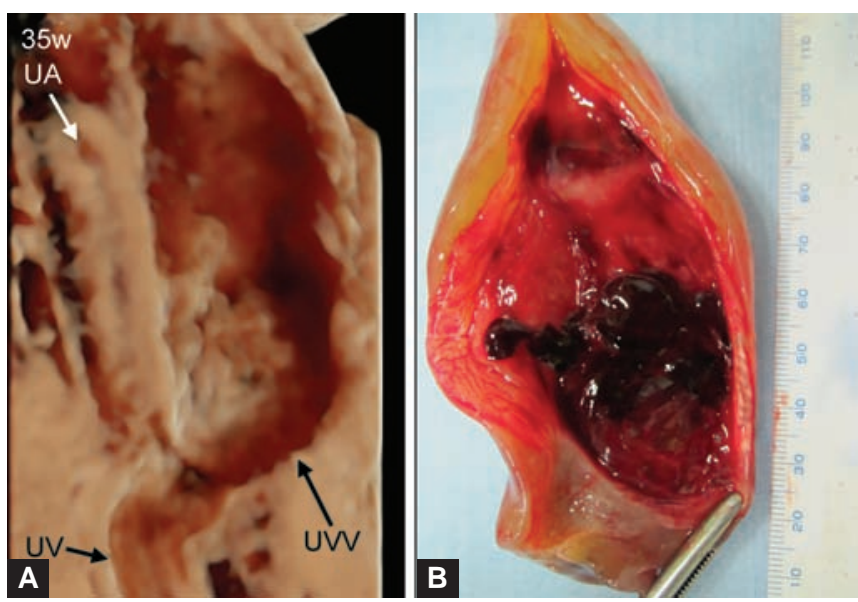

Figs 26A and B: Thrombosis inside the varix. Massive thrombosis inside the varix is evident: (A) HDlive image and (B) gross appearance of longitudinally cut view of the varix (UA: Umbilical artery; UV: Umbilical vein; UVV: Umbilical vein varix) (Courtesy: Reprinted with permission from Hata T et al) ${ }^{14}$

3. Habec D, Kulas T, Selthofer R, Rosso M, Popovic Z, Petrovic D, Ugljarevic M. 3D-ultrasound detection of fetal grasping of the umbilical cord and fetal outcome. Fetal Diagn Ther 2006; 21(4):332-333.

4. Bonilla F Jr, Raga F, Villalaiz E, Osborne N, Castillo JC, Bonilla-Musoles F. Umbilical cord cysts. Evaluation with different 3-dimensional sonographic modes. J Ultrasound Med 2010;29(2):281-285.

5. Jo YS, Kim MJ, Lee GSR, Kim SJ. A large amniocele with protruded umbilical cord diagnosed by 3D ultrasound. Int J Med Sci 2012;9(2):387-390.

6. Hanaoka U, Tenkumo C, Ito M, Mori N, Tanaka H, Hata T. Three-dimensional surface-rendered imaging of cord entanglement in monoamniotic twins. Arch Gynecol Obstet 2012;286(4):1091-1092.

7. Sato M, Kanenishi K, Ito M, Tanaka H, Takemoto M, Hata T. Antenatal 3-D sonographic features of uterine synechia. J Obstet Gynaecol Res 2013;39(1):395-398

8. Ratanasiri T, Doankum C, Kleebkaew P, Kiatchoosakun P. Prenatal three dimensional ultrasonography and expectant management of placental chorioangioma: a case report. J Med Assoc Thai 2013;96(4):496-500.

9. Guzikowski W, Kowalczyk D, Wiecek J. Diagnosis of true umbilical cord knot. Arch Med Sci 2014;10(1):91-95.

10. Hata T, Tanaka H, Noguchi J, Hata K. Three-dimensional ultrasound evaluation of the placenta. Placenta 2011;32(2):105-115.

11. Hata T, Hanaoka U, Tenkumo C, Sato M, Tanaka H, Ishimura M. Three- and four-dimensional HDlive rendering images of normal and abnormal fetuses: pictorial essay. Arch Gynecol Obstet 2012;286(6):1431-1435.

12. Hata T, Tenkumo C, Sato M, Kanenishi K, Ishimura M. Threedimensional HDlive rendered images of intrauterine abnormalities during pregnancy. J Med Ultrasonics 2013;40(2):179-180.

13. Hata T. HDlive rendering image at 6 weeks of gestation. J Med Ultrasonics 2013;40(4):495-496.

14. Kanenishi K, Nitta E, Mashima M, et al. HDlive imaging of intra-amniotic umbilical vein varix with thrombosis. Placenta 2013;34(11):1110-1112.

15. Mashima M, Tanaka H, Ishibashi M, Katayama T, Hata T. HDlive imaging of vertical, bridging uterine synechia during pregnancy. J Med Ultrasonics 2014;41(4):521-524. 
16. Abramowicz JS, Sheiner E. Ultrasound of the placenta: a systematic approach. Part I: Imaging. Placenta 2008;29(3): 225-240.

17. Jauniaux E, Campbell S. Ultrasonographic assessment of placental abnormalities. Am J Obstet Gynecol 1990;163(5 pt 1): 1650-1658.

18. Kagan KO, Pintoffl K, Hoopmann M. First-trimester ultrasound images using HDlive. Ultrasound Obstet Gynecol 2011;38(5):607.

19. Merz E. Surface reconstruction of a fetus $(28+2 \mathrm{GW})$ using HDlive technology. Ultraschall in Med 2012;33(3):211-212.

20. Harris RD, Couto C, Karpovsky C, Porter MMB, Ouhilal S. The chorionic bump: a first-trimester pregnancy sonographic finding associated with a guarded prognosis. J Ultrasound Med 2006;25(6):757-763.

21. Sana Y, Appiah A, Davison A, Nicolaides KH, Johns J, Ross JA. Clinical significance of first-trimester chorionic bumps: a matched case-control study. Ultrasound Obstet Gynecol 2013;42(5):585-589.

22. Katz VL, Blanchard GF Jr, Watson WJ, Miller RC, Chescheir NC, Thorp JM Jr. The clinical implications of subchorionic placental lucencies. Am J Obstet Gynecol 1991;164(1 pt 1):99-100.

23. Deans A, Jauniaux E. Prenatal diagnosis and outcome of subchorionichematomas. Ultrasound Obstet Gynecol 1998;11(5):319-323.

24. Jauniaux E, Ramsay B, Campbell S. Ultrasonographic investi-gation of placental morphologic characteristics and size during the second trimester of pregnancy. Am J Obstet Gynecol 1994;170(1 pt 1):130-137.

25. McCarthy J, Thurmond AS, Jones MK, Sistron C, Scanlan RM, Jacobson L, Lowensohn R. Circumvallate placenta: sonographic diagnosis. J Ultrasound Med 1995;14(1):21-26.

26. Shen O, Golomb E, Lavie O, Goldberg Y, Eitan R, Rabinowitz RR. Placental shelf: a common, typically transient and benign findings on early second-trimester sonography. Ultrasound Obstet Gynecol 2007;29(2):192-194.

27. Hata T, Fujiwara T, Ishibashi M, Kuwamura E, Tenkumo C, Ishihara G. Antenatal here-dimensional sonographic features of placental shelf. J Med Ultrasonics 2012;39(1):43-44.

28. Mahony BS, Filly RA, Callen PW, Golbus MS. The amniotic band syndrome: antenatal sonographic diagnosis and potential pitfalls. Am J Obstet Gynecol 1985;152(1):63-68.

29. Finberg HJ. Uterine synechiae in pregnancy: expanded criteria for recognition and clinical significance in 28 cases. J Ultrasound Med 1991;10(10):547-555.
30. Bäumler M, Faure JM, Counter A, Flunker S, Boulot P. Prenatal 3D ultrasound and MRI assessment of horizontal uterine synechia. Prenata Diagn 2008;28(9):874-875.

31. Benirschke K. Obstetrically important lesions of the umbilical cord. J Reprod Med 1994;39(4):262-272.

32. Pollack MS, Bound LM. Hemangioma of the umbilical cord. J Ultrasound Med 1989;8(3):163-166.

33. Strong TH, Elliott JP, Radin TG. Non-coiled umbilical blood vessels: a new marker for the fetus at risk. Obstet Gynecol 1993;81(3):409-411.

34. Collins JH, Collins CL, Weekwerth SR, De Angelis L. Nuchal cords: timing of prenatal diagnosis and duration. Am J Obstet Gynecol 1995;173(3 pt 1):768.

35. Aoki S, Hata T, Ariyuki Y, Makihara K, Hata K, Kitao M. Antenatal diagnosis of aberrant umbilical vessels. Gynecol Obstet Invest 1997;43(4):232-235.

36. Tepper R, Kidron D, Aviram R, Markovitch O, Hershkovitz R. High incidence of cord entanglement during early pregnancy detected by three-dimensional sonography. Am J Perinatol 2009;26(5):379-382.

37. Hanaoka U, Yanagihara T, Tanaka H, Hata T. Comparison of three-dimensional, two-dimensional and color Doppler ultrasound in predicting the presence of a nuchal cord at birth. Ultrasound Obstet Gynecol 2002;19(5):471-474.

38. Dulnuan DJ, Matsuoka M, Uketa E, Hayashi K, Murotsuki J, NishimuraG,Hata T. Antenatal three-dimensional sonographic features of Roberts syndrome. Arch Gynecol Obstet 2011;284(1): 241-244.

39. Vesce F, Guerrini P, Perri G, Gavazzini L, Simonetti V. Ultrasonographic diagnosis of ectasia of the umbilical vein. J Clin Ultrasound 1987;15(5):346-349.

40. Shipp TD, Bromley B, Benacerraf BR. Sonographically detected abnormalities of the umbilical cord. Int J Gynecol Obstet 1995;48(2):179-185.

41. Cruise KRL, Rouse G. Klippel-Trenaunay-Weber syndrome complicated by extrafetal umbilical vein varix. J Diagn Med Sonography 2002;18(5):317-320.

42. Tröbs RB, Teig N, Neid M, Gernaianu G, Kozlowski P. Pseudotumerous enlargement of the umbilical cord owing to an intra-amniotic varicosity associated with thrombocytopenia. J Pediatr Surg 2012;47(9):1760-1762. 